\title{
Effect of Dynamic Properties of Support O-Rings on Stability of Herringbone-Grooved Aerodynamic Journal Bearings
}

\author{
Norifumi Miyanaga $^{1)^{*}}$ and Jun Tomioka ${ }^{2)}$ \\ ${ }^{1)}$ Department of Science and Engineering, Kanto-Gakuin University \\ 1-50-1 Mutsuurahigashi, Kanazawa-ku, Yokohama, Japan \\ ${ }^{2)}$ Faculty of Science and Engineering, Waseda University \\ 3-4-1 Okubo, Shinjuku-ku, Tokyo, Japan \\ *Corresponding author: miyanaga@kanto-gakuin.ac.jp
}

( Manuscript received 28 October 2015; accepted 14 February 2016; published 30 April 2016 )

( Presented at the International Tribology Conference Tokyo 2015, 16-20 September, 2015 )

\begin{abstract}
This paper discusses the stability of herringbone-grooved aerodynamic journal bearings supported by rubber O-rings. In this research, the dynamic stiffness and the damping properties of the O-rings are identified in a variety of operating and design conditions. The identification results are fitted with the empirical formulae previously proposed, and the distributions of the dynamic properties in a variety of support conditions are obtained. It is theoretically investigated how the stability of the bearing system changes with the dynamic properties. The bearing tests are also performed to verify the analytical results with the empirical formulae. The empirical formulae used here was reasonable for simulating the dynamic properties of the O-rings in a variety of bearing support conditions. The comparisons between the analysis and experiments verified the effectively of analyzing the stability of the bearing system by using the empirical formulae.
\end{abstract}

Keywords: herringbone bearings, aerodynamic journal bearing, whirl instability, dynamic properties of rubber O-rings

\section{Introduction}

Gas-lubricated bearings are utilized in a variety of applications from small instruments to large turbomachinery, and they are particularly attractive for use in high-speed applications because of the low viscosity [1]. However, for high-speed operations, they have the weakness in dynamic problems, especially in the self-excited whirl instability. Flexibly supported journal bearings are often used to improve the stability. This stabilization approach was investigated theoretically by Lund [2] at the first. In the literature, it was qualitatively shown that the flexible support of the bearing sleeve could raise the threshold speed at which the loss of stability occurs. Powell et al. [3] and Kazimierski et al. [4] discussed the stability of an externally pressurized gas bearing sustained by rubber O-rings and concluded that the use of the O-rings lead to a higher whirl onset speed. In such bearing system, a bearing sleeve was allowed to move to follow a rotating shaft. Therefore, the bearing system could receive an additional damping effect from external structures.

In recent years, this type of bearing systems has attracted considerable attention with a need for increasing rotational speed in small-sized rotational machinery [5-7]. Foil bearings have been also investigated as a promising candidate, but their structures and performance are still uncontrolled. On the other hand, herringbone-grooved aerodynamic bearings are easy to manufacture and widely employed $[8,9]$. Also they have improved threshold of whirl instability owing to the self-pumping effect by narrow grooves scribed on either a rotating or stationary member. The performance of the bearing strongly depends on the groove configurations. Therefore, many papers concerning optimal herringbone groove configurations were already published [10-13]. However, few papers discussed the stability of the bearings with viscoelastic supports.

Hirasaka et al. [14] developed a herringbone grooved floating bush bearing supported by an aerostatic bearing, and they theoretically confirmed its static performance. Then, Yoshimoto et al. [15] proposed a herringbone grooved aerodynamic floating bush bearing flexibly supported by three- or fourlayered foils with hemispherical bumps. They demonstrated that a shaft supported by the proposed bearings was operated stably at higher speeds compared with conventional herringbone grooved bearings which 
were rigidly mounted. On the other hand, the authors $[16,17]$ have been investigating the stability of herringbone-grooved aerodynamic journal bearings supported by rubber O-rings and reported that the bearing systems had higher stability than rigidly supported ones. However, the proper bearing support conditions are not made clear yet. One main reason for the difficulty would be that the dynamic stiffness and damping of the O-rings depend on the operating conditions such as excitation frequency and temperature of the bearing system, as well as the design factors such as the materials and the deformation ratios of the O-rings. The authors [18] already confirmed from the comparison of the analysis and the experiment that it was possible to predict the whirl onset speed accurately by considering the frequency dependence of the support stiffness and damping of the O-rings. Then, the empirical formulae with a clear physical meaning were proposed to be able to treat the dynamic properties of the O-rings in various bearing support conditions $[19,20]$. In the latest research, Somaya et al. [21] also calculated the instability threshold of an aerodynamic herringbone-grooved journal bearing flexibly supported by straight spring wires, considering the frequency dependence of their dynamic stiffness and damping, and they got a good agreement with the experiments.

In this research, the dynamic properties of the O-rings are identified in a variety of operating and design conditions, including the deformation ratio of the O-rings whose effect is never focused yet. The results are fitted with the empirical formulae previously proposed, and the distributions of the dynamic properties in a variety of support conditions are obtained. Then, it is theoretically investigated how the stability of the bearing system changes with the dynamic properties. Finally, the bearing tests are performed to verify the analytical results with the empirical formulae.

\section{Bearing system}

Figure 1 shows the bearing system analyzed in this research. A rotating shaft with no unbalance is symmetric and symmetrically supported by identical herringbonegrooved aerodynamic journal bearings at its both ends. A bearing sleeve with herringbone grooves is mounted on rubber O-rings in a housing. In this research, the

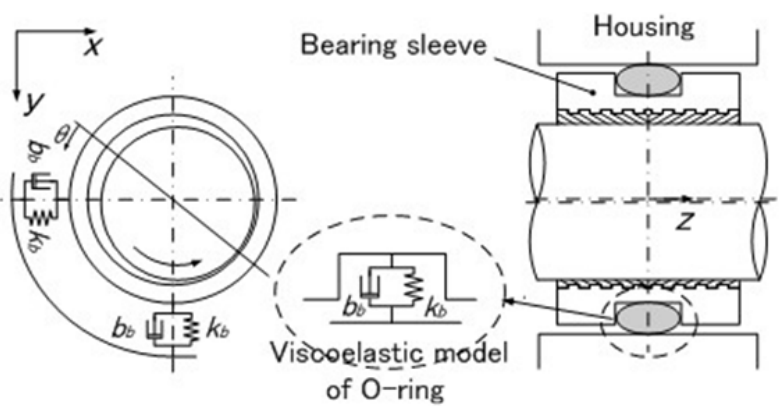

Fig. 1 Herringbone-grooved aerodynamic journal bearings mounted on rubber O-rings

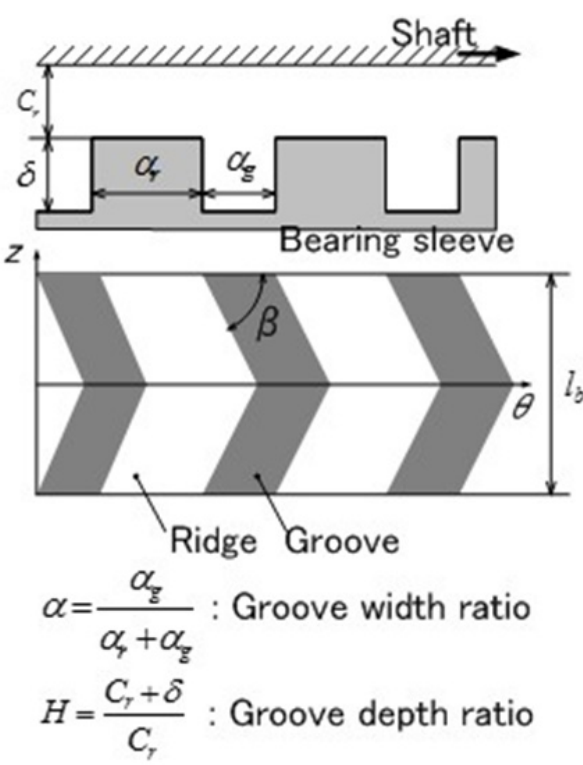

Fig. 2 Geometry of herringbone grooves

viscoelasticity of the rubber O-rings are expressed by the Voight model as shown in this figure. It is assumed that the properties in the vertical and horizontal directions are identical. The bearing sleeve can move in $x$ - and $y$-directions with the cylindrical vibration of the shaft. Figure 2 shows the parameters of herringbone grooves used in this analysis.

\section{Formulation of dynamic properties of the O-rings}

3.1. Identification of stiffness and damping coefficients

The stability of the bearing system strongly depends on the dynamic properties of the O-rings as well as the aerodynamic film properties. For the stability analysis, therefore, it is desirable to formulate the dynamic properties. For this purpose, the stiffness and damping coefficients of the O-rings are experimentally obtained first, using the measurement system shown in Fig.3. In this system, a bearing sleeve is mounted on rubber O-rings. The housing is bolted on an exciter and the bearing sleeve is oscillated in its radial direction in the frequency range from 0.5 to $8.0 \mathrm{kHz}$. The oscillation

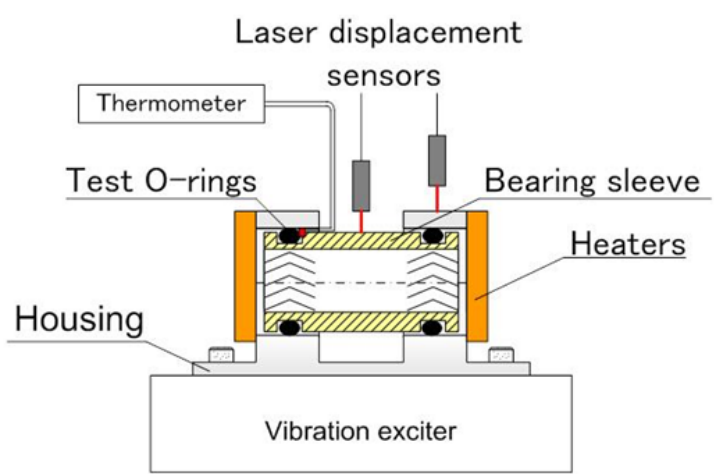

Fig. 3 Measurement device for identifying the stiffness and damping coefficients of the O-rings supporting the bearing sleeve 
Table 1 Measurement conditions

\begin{tabular}{l|c}
\hline \hline Temperature $T[\mathrm{~K}]$ & $293-333$ \\
\hline Deformation ratio $\gamma[-]$ & $0.23-0.30$ \\
\hline Vibration frequency $f_{p}[\mathrm{kHz}]$ & $0.5-8.0$ \\
\hline \multirow{3}{*}{ Materials } & NBR(Nitrile butadiene rubber) \\
& SBR(Styrene butadiene rubber) \\
& VMQ(Vinyl methyl silicone)
\end{tabular}

Table 2 Characteristics of test O-rings

\begin{tabular}{l|c|c|c}
\hline \hline Material & NBR & SBR & VMQ \\
\hline Durometer hardness [-] & 72 & 72 & 72 \\
\hline Tensile strength [MPa] & 17.6 & 15.7 & 6.0 \\
\hline Elongation [\%] & 380 & 380 & 190 \\
\hline Young's modulus [MPa] & 4.2 & 3.8 & 2.4 \\
\hline
\end{tabular}

simulates the bearing excitation when the journal starts whirling around its equilibrium position. The displacements of the bearing sleeve and housing are measured by laser displacement sensors.

The stiffness and damping coefficients of the O-rings depend on various conditions. In this research, therefore, the identification is performed under the conditions shown in Table 1. The test O-rings are made of nitrile rubber, styrene rubber and silicone rubber, whose standard data are listed in Table 2 [22]. The temperature of the measurement system (housing, bearing sleeve, and O-rings) is controlled by heaters mounted on the housing. The deformation ratio of the O-rings is defined as Eq. (1).

$$
\gamma=\frac{2 s-\left(d_{1}-d_{2}\right)}{2 s}
$$

where $s$ is the thickness of the O-rings, $d_{1}$ is the inner diameter of the housing $(16.8 \mathrm{~mm})$, and $d_{2}$ is the outer diameter of the bearing sleeve $(14.6 \mathrm{~mm})$. The bearing sleeve and housing are made of copper alloy (linear expansively: $19 \times 10^{-6} 1 / \mathrm{K}$ ) and aluminum alloy (linear expansively: $\left.23 \times 10^{-6} 1 / \mathrm{K}\right)$, respectively. The distance $\left(d_{1}-d_{2}\right)$ changes less than $0.2 \%$ with variations in temperature from 293 to $333 \mathrm{~K}$. Therefore, the thermal effect on the deformation ratio can be neglected in this identification.

Figure 4 is an example of measurement data (plots). Approximating the input and response data as Eqs. $(2,3)$, respectively, one can obtain the oscillation amplitudes, $A_{\text {in }}$ and $A_{\text {out }}$, and the phase difference $\varphi$.

$$
\begin{array}{ll}
z_{\text {in }}=A_{\text {in }} \sin \left(2 \pi f_{p} t\right) & {[\mathrm{m}]} \\
z_{\text {out }}=A_{\text {out }} \sin \left(2 \pi f_{p} t-\varphi\right) & {[\mathrm{m}]}
\end{array}
$$

Then, the amplitude ratio $A=A_{\text {out }} / A_{\text {in }}$ and the phase difference $\varphi$ are substituted into Eqs. $(4,5)$ to determine the stiffness $k_{b}$ and damping coefficients $b_{b}$.

$$
k_{b}=\frac{2 \pi^{2} A(A-\cos \varphi) m_{b} f_{p}^{2}}{A^{2}-2 A \cos \varphi+1} \quad[\mathrm{MN} / \mathrm{m}]
$$

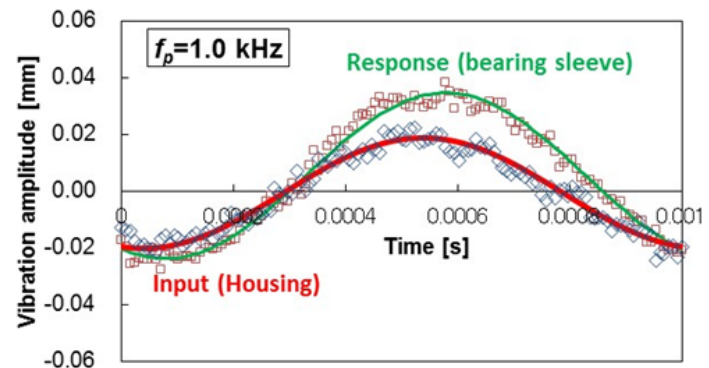

Fig. 4 Analysis of measurement data $\left(f_{p}=1 \mathrm{kHz}\right)$

$$
b_{b}=\frac{\pi A m_{b} f_{p} \sin \varphi}{A^{2}-2 A \cos \varphi+1} \quad[\mathrm{kN} \cdot \mathrm{s} / \mathrm{m}]
$$

where $m_{b}$ is the mass of the bearing sleeve and $f_{p}$ is the excitation frequency.

In the past publication, Tomioka and Miyanaga [18] expressed the both coefficients by cubic equations in the frequency range less than $4.0 \mathrm{kHz}$. However, the cubic equations cannot accurately fit the stiffness and damping coefficients in the wide frequency range, from 0.5 to $8.0 \mathrm{kHz}$. In addition, it is difficult to understand the physical meaning of approximate expressions. Therefore, the authors $[19,20]$ have proposed the empirical formulae for the stiffness and damping coefficients, as shown in Eqs. $(6,7)$, respectively.

$$
\begin{array}{ll}
k_{b}=k^{\prime} \exp \left(k^{\prime \prime} f_{p}\right) & {[\mathrm{MN} / \mathrm{m}]} \\
b_{b}=b^{\prime}+1 / \exp \left(b^{\prime \prime} f_{p}\right) & {[\mathrm{kN} \cdot \mathrm{s} / \mathrm{m}]}
\end{array}
$$

where $k^{\prime}[\mathrm{MN} / \mathrm{m}], k^{\prime}[1 / \mathrm{kHz}], b^{\prime}[\mathrm{kN} \cdot \mathrm{s} / \mathrm{m}]$ and $b^{\prime \prime}$ $[1 / \mathrm{kHz}]$ are the dynamic properties of the O-rings. These values are determined by the least square method. When the values of $k$ " and $b$ " relating excitation frequency term $f_{p}[\mathrm{kHz}]$ equal to be zero, the stiffness and damping coefficients reduce to the constant values. In addition, the value of $k^{\prime}$ means the stiffness coefficient at $f_{p}=0$.

3.2. Measurement results of stiffness and damping coefficients

Figures 5,6 show the measurement results of the stiffness and damping coefficients (plots), respectively, for the deformation ratios of $\gamma=0.23,0.27$ and 0.30 , as examples. In these measurements, the nitrile rubber O-rings were used and the temperature was made to be about $300 \mathrm{~K}$. The stiffness and damping coefficients increased with the deformation ratio. As the excitation frequency increased, the stiffness coefficient 


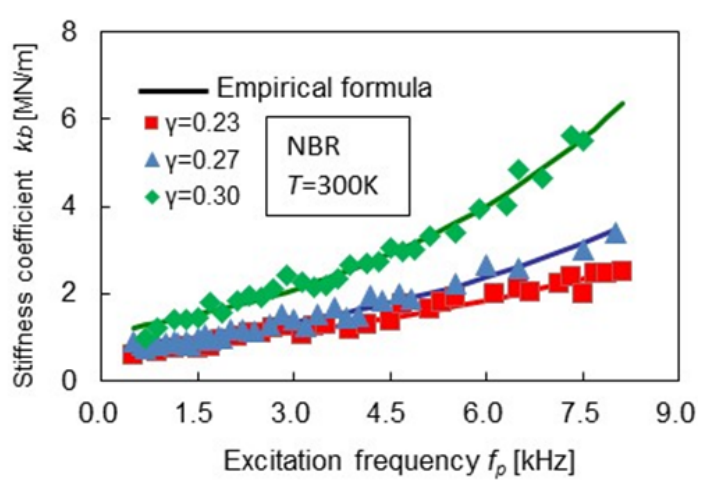

Fig. 5 The stiffness coefficients of the O-rings for $\gamma=0.23,0.27$ and 0.30

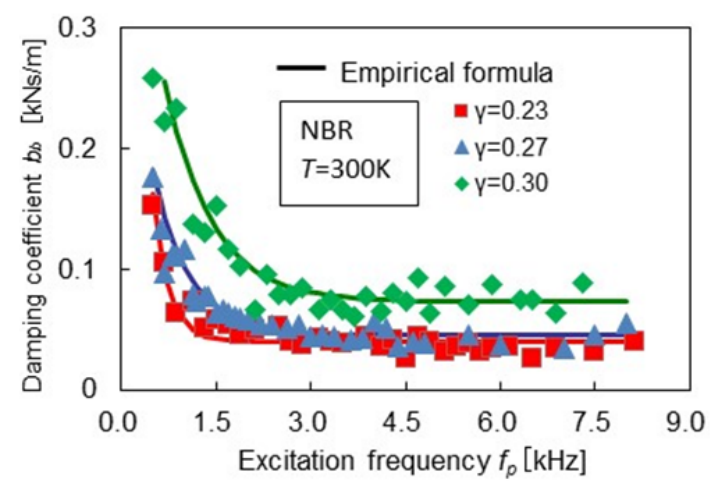

Fig. 6 The damping coefficients of the O-rings for $\gamma=0.23,0.27$ and 0.30

exponentially increased whereas the damping coefficient decreased. These trends could be well characterized with the empirical formulae, Eqs. $(6,7)$. The determination coefficients $\mathrm{R}^{2}$ for the results were more than 0.9 in all cases. The measurement results when the O-ring material or temperature was changed have been already shown in the literatures $[19,20]$. According to the literatures, the effects of the temperature and the materials of the O-rings on both coefficients were also well characterized by these empirical formulae in the frequency range from 0.5 to $8.0 \mathrm{kHz}$. These results lead to that it is possible to simulate various O-ring support conditions by Eqs. $(6,7)$ within the range of the measurement condition shown in Table 1. Table 3 shows the distribution of the dynamic properties of the O-rings obtained under the measurement conditions shown in Table 1.

Table 3 Distribution of the dynamic properties obtained from this research

\begin{tabular}{c|c}
\hline \hline$k^{\prime}[\mathrm{MN} / \mathrm{m}]$ & $0.1-10$ \\
\hline$k^{\prime}[1 / \mathrm{kHz}]$ & $0-0.5$ \\
\hline$b^{\prime}[\mathrm{kNs} / \mathrm{m}]$ & $0.05-0.2$ \\
\hline$b^{\prime \prime}[1 / \mathrm{kHz}]$ & $0-8$ \\
\hline
\end{tabular}

\section{Stability analysis of the bearing system}

\subsection{Summary of analytical method}

Figure 7 shows an analytical model of the bearing system. The dynamic stiffness and damping of the O-rings are calculated by Eqs. $(6,7)$ for various support conditions, considering the whirl frequency of the shaft. In this research, the effects of $k^{\prime}, k^{\prime \prime}, b^{\prime}$ and $b^{\prime \prime}$ on the stability of the bearing system are investigated by the linear perturbation analysis. In this section, the analytical method is briefly mentioned. The detail can be referred to the literature [19].

To obtain the pressure distribution of the lubricating film, the lubrication equation of compressible fluid flow based on the narrow groove theory is solved. In this calculation, it is assumed that the shaft has a small circular whirling motion with the angular velocity of $\omega_{p}$ $\left(=2 \pi f_{p}\right)$ on the stability boundary. Furthermore, it is assumed that the film pressure can be expressed as a linear sum of the static and the perturbation pressures. The changes in the bearing clearance due to the centrifugal growth of the journal and the thermal expansion of the journal and bearing sleeve are also considered. Three boundary conditions are employed to obtain the pressure distribution: the film pressure at the bearing both ends is atmospheric pressure, the film pressure and its gradient in the circular distribution are periodic, and the mass flow rate in the axial direction at the bearing center is zero. By using the film forces obtained from the integration of the linearized film pressure, the equations of motion for the journal and bearing sleeve are derived. Then, the tenth order characteristic equation of the bearing system can be derived.

The threshold speed of whirl instability is determined, as follows.

1. The dynamic properties of the O-rings, $k^{\prime}, b^{\prime}, k^{\prime}$ and $b "$, are given to Eqs. $(6,7)$, simulating a certain bearing support condition.

2. The static pressure and the perturbation pressure are obtained by solving the lubrication equation, using initial values of the bearing number $\Lambda$ and the whirl frequency ratio $v$.

3. Integrating the converged static and perturbation pressures and converting them to the rectangular coordinate, the aerodynamic film force coefficients $k_{i}$ and $b_{i}(i=1,2,3,4)$ shown in Figs. 5,6 are obtained.

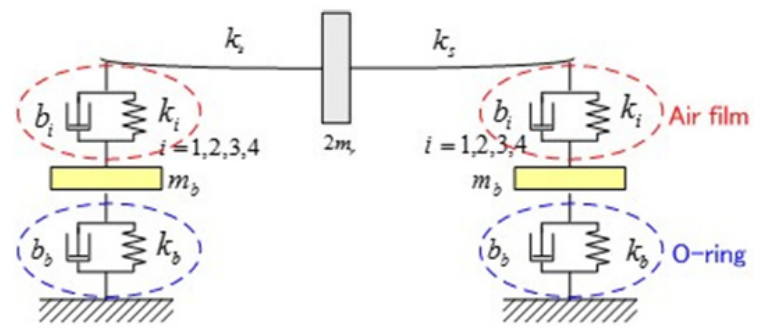

Fig. 7 Analytical model of the bearing system 
4. The whirl frequency is obtained using the bearing number $\Lambda$ and the whirl frequency ratio $v$, shown in Eqs. $(8,9)$. Then, the stiffness and damping coefficients of the O-rings, $k_{b}$ and $b_{b}$, are determined by Eqs. $(6,7)$.

5. New values of the bearing number $\Lambda$ and the whirl frequency ratio $v$ are obtained from the characteristic equation on the stability boundary.

6. By using the bearing number $\Lambda$ and the whirl frequency ratio $v$ obtained from step5, the lubrication equation is solved again.

Step 3-6 are repeated until the bearing number $\Lambda$ and the whirl frequency ratio $v$ are converged. The aforementioned procedure is made for various $k^{\prime}, b^{\prime}, k^{\prime}$ ' and $b$ ".

$$
\begin{aligned}
& \Lambda=\frac{6 \mu \omega R^{2}}{p_{a} C_{r}^{2}} \\
& v=\frac{\omega_{p}}{\omega}
\end{aligned}
$$

where $\mu$ is the viscosity of lubricating air, $\omega$ is the angular velocity of the journal, $R$ is the radius of the journal, $p_{a}$ is the atmospheric pressure, $C_{r}$ is the radial clearance at the ridge part.

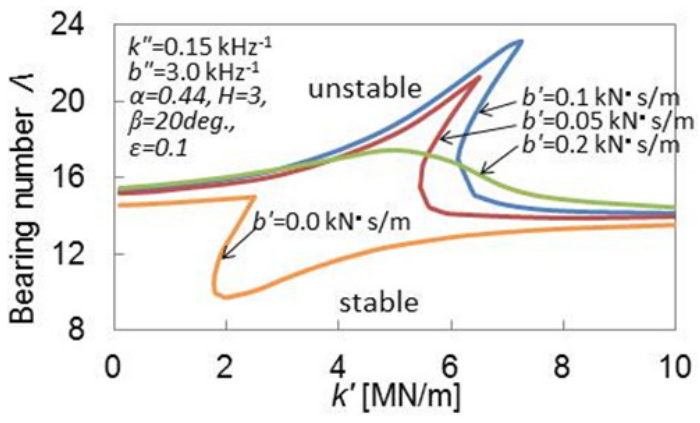

Fig. 8 Variety of stability threshold with $k^{\prime}$ and $b^{\prime}$
4.2. Effect of the dynamic properties of rubber O-rings on the stability of the bearing system

Figure 8 shows the effects of $k^{\prime}$ and $b^{\prime}$ on the threshold speed of whirl instability. In this figure, the values of $k$ " and $b$ " was made to be 0.15 and 3.0, respectively. Nitrile rubber O-rings used had the dynamic properties of $k "=0.15$ and $b "=3.0$ around $T=$ 300 and $\gamma=0.27$. The support stiffness increases as the value of $k$ ' increases. The damping coefficient increases as the value of $b$ ' increases. As seen in Fig. 8, the bearing system had two stable region for $b^{\prime}=0.1$. When the bearing number increased at $k^{\prime}=6.5$, for example, the bearing system turned unstable around $\Lambda=15$ and returned stable around $\Lambda=19.7$. Furthermore, the system turned unstable again at $\Lambda=22$. This interesting phenomenon appeared also for $b^{\prime}=0.05$. When $b^{\prime}=0.2$, the threshold speed was not increased very much, despite higher damping than the others. On the other hand, it was found from the result of $b^{\prime}=0$ that there was the support conditions that the bearing stability decreased. Figure 9 shows the whirl frequency ratio on the stability boundary. The whirl frequency ratio had the values from 0.5 to 0.7 .

In Figs. 10(a-e), the values of $k^{\prime}, b^{\prime}$ and $b^{\prime \prime}$ were

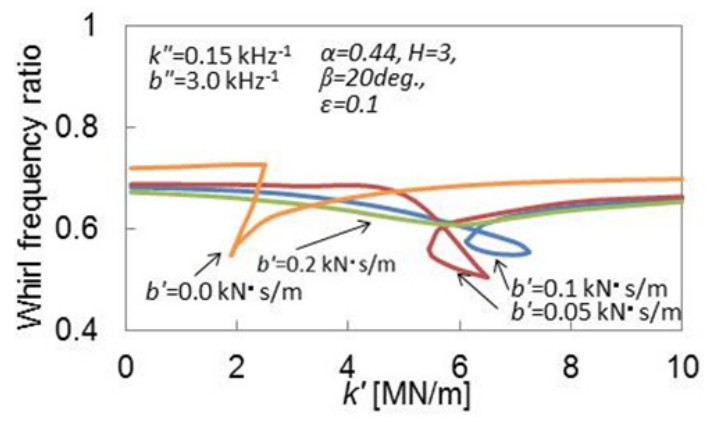

Fig. 9 Whirl frequency ratios on the stability boundary shown in Fig.8

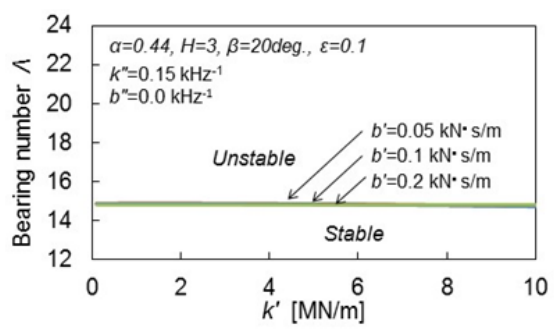

(a) $b^{\prime \prime}=0.0 \mathrm{kHz}^{-1}$

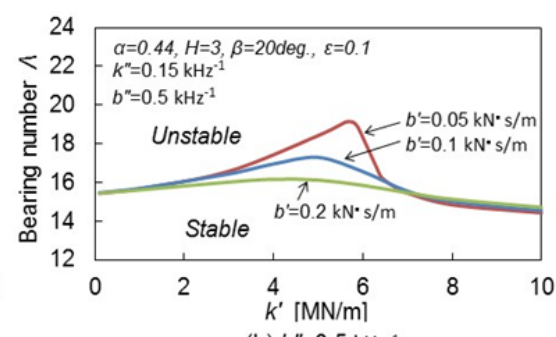

(b) $b=0.5 \mathrm{kHz}^{-1}$

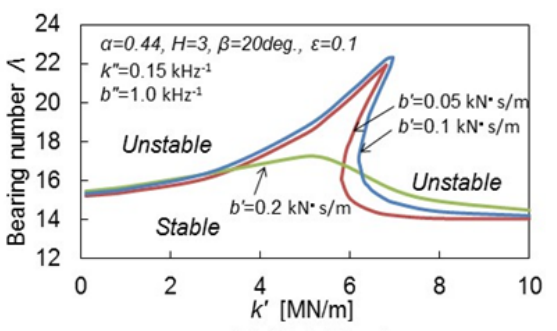

(c) $b^{\prime \prime}=1.0 \mathrm{kHz}^{-1}$

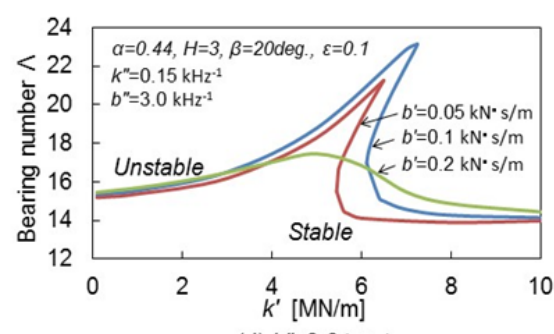

(d) $b^{\prime \prime}=3.0 \mathrm{kHz}^{-1}$

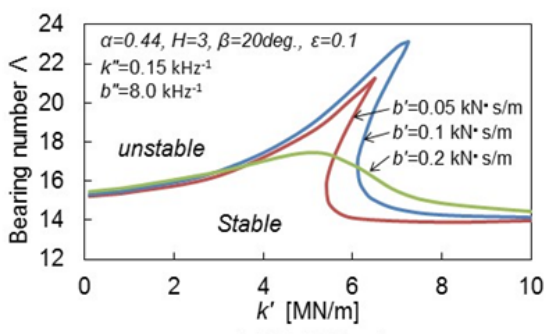

(e) $b "=5.0 \mathrm{kHz}^{-1}$

Fig. 10 Effect of the dynamic properties on the stability threshold of the bearing system $(k "=0.15)$ 


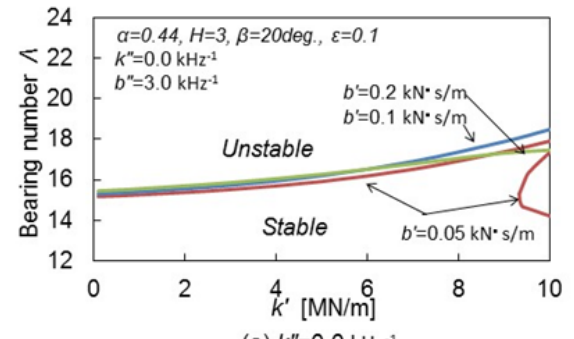

(a) $k^{\prime \prime}=0.0 \mathrm{kHz}^{-1}$

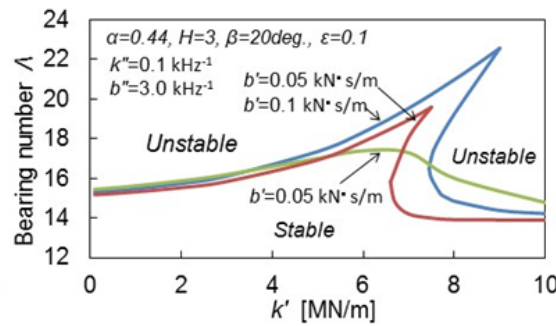

(b) $k^{\prime \prime}=0.1 \mathrm{kHz}^{-1}$

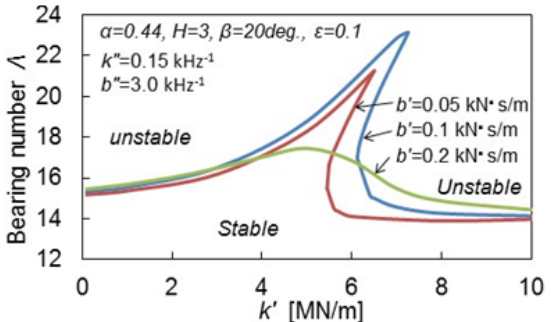

(c) $k^{\prime \prime}=0.15 \mathrm{kHz}^{-1}$

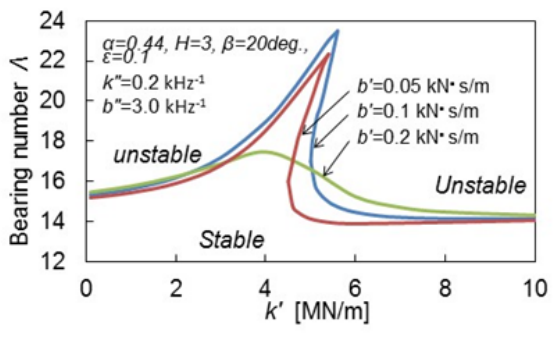

(d) $k^{\prime \prime}=0.2 \mathrm{kHz}^{-1}$

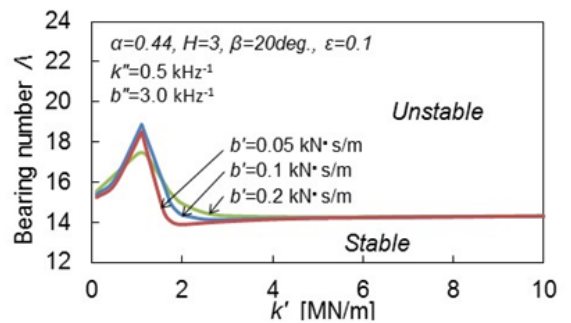

(e) $k^{\prime \prime}=0.5 \mathrm{kHz}^{-1}$

Fig. 11 Effect of the dynamic properties on the stability threshold of the bearing system $(b "=3.0)$

changed whereas $k "=0.15$ as Fig. 8. From Fig. 10(a), the effect of the O-ring supports did not appear when $b$ " $=0$, regardless of the values of $k^{\prime}$ and $b^{\prime}$ studied. According to Eq. (7), the damping coefficient is larger as the value of $b$ " is closer to zero. Therefore, it can be concluded that the advantage of the O-ring supports disappears when the support damping is larger than its proper value. In Figs. 10(b-e), the effect of the O-ring supports appeared around $k^{\prime}=4-7$. For $b^{\prime}=0.5$, the bearing system had the highest threshold speed when $b^{\prime}$ $=0.05$. However for $b ">1$, the threshold speed reached the highest value when $b^{\prime}=0.1$. In Eq. (7), the influence of the second term vanishes compared to the first term as the values of $b$ " increases. For this reason, the effect of $b$ " disappeared for the larger values of $b$ " studied, as shown in Figs. 10(d,e).

In Figs. 11(a-e), the values of $k^{\prime}, b^{\prime}$ and $k^{\prime \prime}$ were changed whereas $b "=3.0$ as Fig. 8. In Fig. 11, the threshold speed reached the highest value when $b^{\prime}=0.1$. The value of $k$ ' that gave the highest threshold speed decreased when the value of $k$ " increased. In addition, it could be seen that when $k "=0.5$, the stabilization effect by the O-ring supports was getting smaller. This is because that for stiffer support conditions, the bearing sleeve cannot follow the journal vibration, as well as the rigid support system. From the analytical results shown in Figs. 10,11, the bearing system had the largest stability region when the dynamic properties of the O-rings were $k^{\prime}=5, k^{\prime \prime}=0.2, b^{\prime}=0.1, b ” \geqq 3$.

\section{Experiments}

\subsection{Experimental apparatus and method}

In section 4.2 , the effects of $k^{\prime}, k^{\prime}, b^{\prime}$ and $b^{\prime \prime}$ on the stability criterion of the bearing system were analyzed. In this section, the bearing tests are performed for the case of three deformation ratios, $\gamma=0.23,0.27$ and 0.30 , and compared to the analysis.
Figures 12,13 show a cross section and a picture of a bearing test device, respectively. A smooth shaft is supported by herringbone-grooved aerodynamic journal bearings. The shaft is driven by an air turbine located at its upper end and the rotational speed is measured by an optical fiber sensor. The behaviors of the shaft are monitored by eddy-current displacement sensors and at

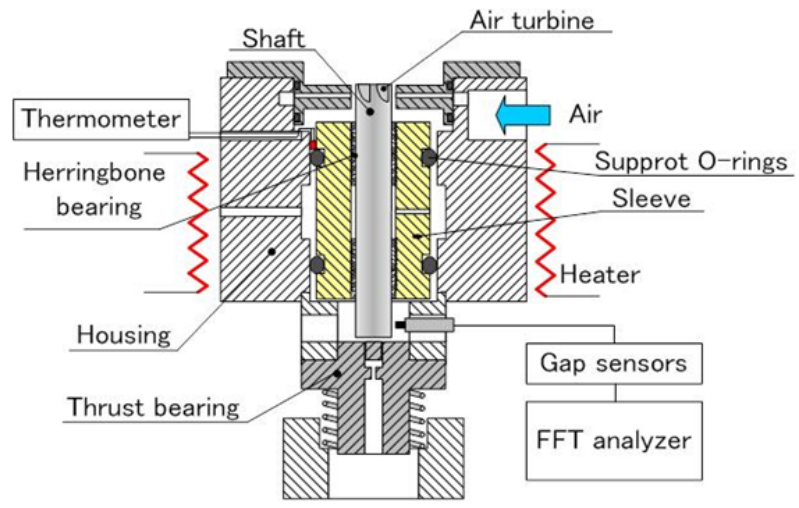

Fig. 12 Cross section of bearing test device

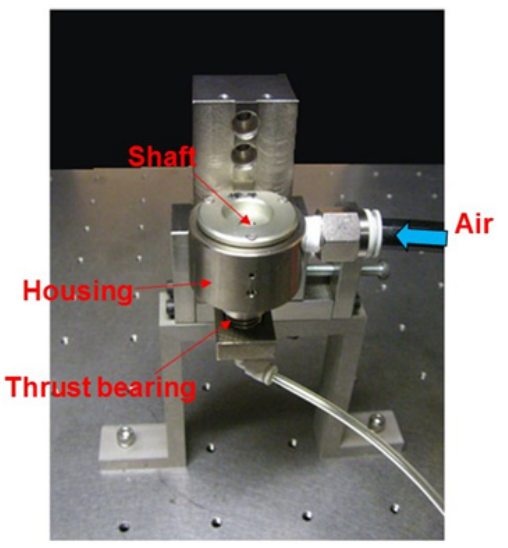

Fig. 13 Picture of bearing test device (heaters and sensors are not shown here) 
Table 4 Dimensions of shaft, bearing sleeve and herringbone-grooves

(a) Shaft

\begin{tabular}{l|c}
\hline \hline Shaft diameter $d[\mathrm{~mm}]$ & 6 \\
\hline Shaft length $l_{s}[\mathrm{~mm}]$ & 30.75 \\
\hline Mass of shaft $m_{s}[\mathrm{~g}]$ & 2.35 \\
\hline
\end{tabular}

(b) Bearing sleeve

\begin{tabular}{l|c}
\hline \hline Radial clearance $C_{r}[\mu \mathrm{m}]$ & 4 \\
\hline Bearing length $l_{b}[\mathrm{~mm}]$ & 6 \\
\hline Mass of sleeve $m_{b}[\mathrm{~g}]$ & 28.2 \\
\hline
\end{tabular}

(c) Herringbone-grooves

\begin{tabular}{l|c}
\hline \hline Groove width ratio $\alpha[-]$ & 0.44 \\
\hline Groove angle $\beta[\mathrm{deg}]$ & 20 \\
\hline Groove depth $\delta[\mu \mathrm{m}]$ & 8 \\
\hline Groove number $N_{g}$ & 24 \\
\hline
\end{tabular}

the same time the measurements are analyzed by FFT. Table 4 shows the dimensions of the shaft, bearing sleeve and herringbone grooves. The deformation ratio of the O-rings shown in Eq. (1) are controlled by varying the inner diameter of the housing $\left(d_{1}\right)$. The temperature is controlled by heaters and a thermometer mounted on the housing.

\subsection{Comparison of experiments and analysis}

Figure 14 shows experimental results, comparing to the analytical ones. The solid line represents the threshold speed that was predicted by using the identification results of the O-rings shown in Figs. 5,6. The threshold speed slightly increased as the deformation ratio increased. In this calculation, the following relations between the dynamic properties and the deformation ratio were used.

$$
\begin{array}{ll}
k^{\prime}=5.57 \gamma-0.636 & {[\mathrm{MN} / \mathrm{m}]} \\
k^{\prime}=0.754 \gamma-0.0111 & {[1 / \mathrm{kHz}]} \\
b^{\prime}=0.483 \gamma-0.074 & {[\mathrm{kN} \cdot \mathrm{s} / \mathrm{m}]}
\end{array}
$$

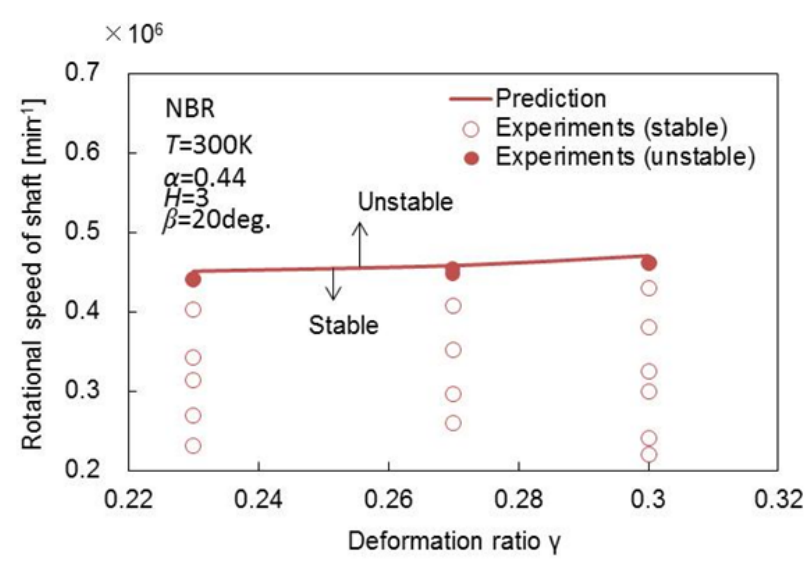

Fig. 14 Predicted and experimented stability limit of the bearing system

$$
b "=-33.3 \gamma+11.8 \quad[1 / \mathrm{kHz}]
$$

In Fig. 14 the open plots are the results for the stable operations whereas the closed plots are for the unstable operations. The whirl instability was induced at slightly lower rotational speed compared to the analytical prediction. Figure 15 shows the waterfall diagram of the power spectrum of the shaft vibration during increasing the rotation speed, for the deformation ratio of $\gamma=0.27$. It can be seen that the whirl instability was observed at the rotational speed over $7.3 \mathrm{kHz}\left(438,000 \mathrm{~min}^{-1}\right)$. In addition, Fig. 16 shows the comparison of the whirl frequency ratio obtained from the experiment and theoretical prediction. From Figs. 14-16, it can be concluded that the comparisons verify the effectivity of analyzing the stability of the bearing system by the empirical formulae Eqs. $(6,7)$. Also it would be possible by using the equations to find the proper support conditions that provide higher stability to the bearing system.

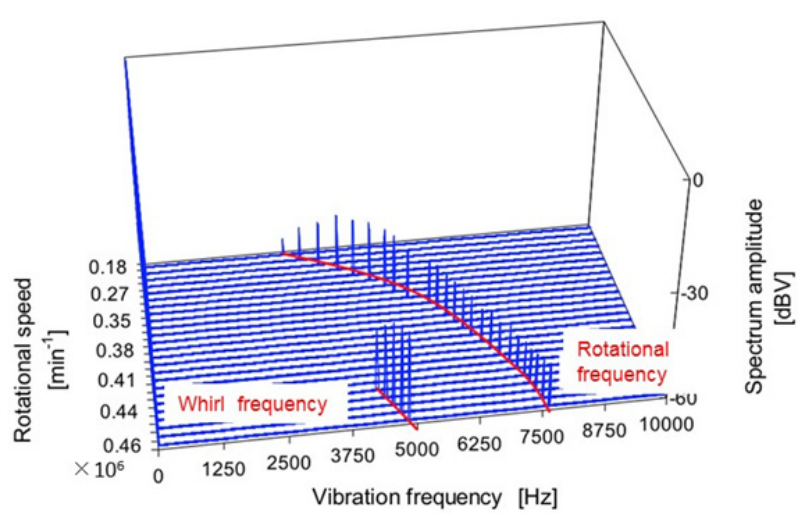

Fig. 15 Waterfall diagram of the power spectrum of the shaft vibration

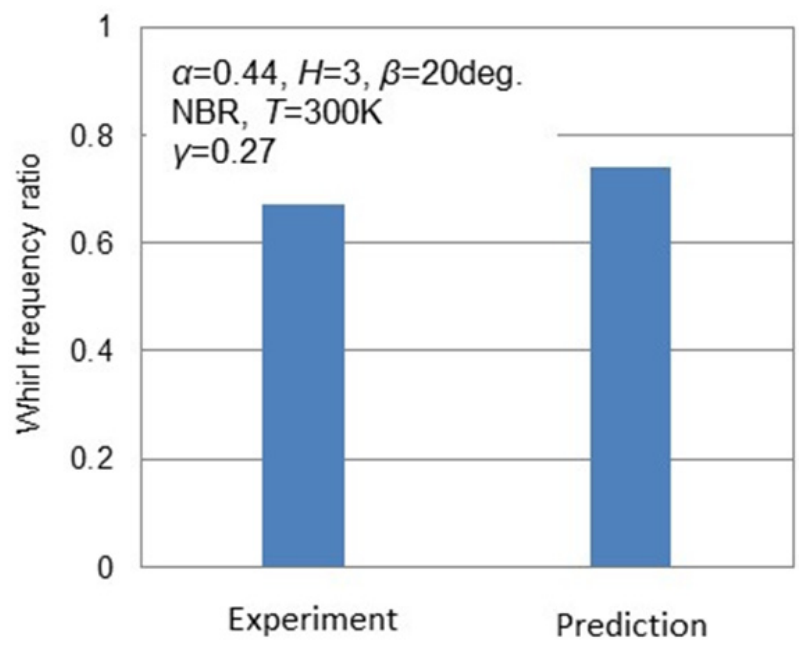

Fig. 16 Comparison of whirl frequency ratios obtained from experiment and theoretical prediction 


\section{Conclusions}

(1) As the excitation frequency increased, the stiffness coefficient increased whereas the damping coefficient decreased. Both coefficients increased as the deformation ratio increased. The empirical formulae used here was reasonable for simulating the dynamic properties of the O-rings in a variety of bearing support conditions.

(2) By using the empirical formulae, the effects of the dynamic properties of the O-rings, $k^{\prime}, k^{\prime}, b^{\prime}$ and $b$ ", on the stability of the bearing system were investigated. The support conditions with smaller values of $b$ " could not improve the stability. The bearing system had the largest stable region when the values were $k^{\prime}=5, k^{\prime \prime}=0.2, b^{\prime}=0.1, b^{\prime \prime} \geqq 3$, among the various combinations of the dynamic properties studied.

(3) The bearing tests were performed for the cases of the deformation ratios of $\gamma=0.23,0.27$ and 0.30 , and compared to the analysis. The comparisons verified the effectivity of analyzing the stability of the bearing system by the empirical formulae.

\section{Acknowledgement}

This work was supported by JSPS KAKENHI Grant Number 26420089.

\section{Nomenclature}

$A$ amplitude ratio $=A_{\text {out }} / A_{\text {in }}$

$A_{\text {in }}$ amplitude of the input oscillation [m]

$A_{\text {out }}$ amplitude of the response oscillation [m]

$b_{b}$ damping coefficient of O-rings $[\mathrm{kN} \cdot \mathrm{s} / \mathrm{m}]$

$b_{i} \quad$ damping coefficients of air film $(i=1,2,3,4)$ $[\mathrm{kN} \cdot \mathrm{s} / \mathrm{m}]$

$b$ dynamic properties of O-rings $[\mathrm{kN} \cdot \mathrm{s} / \mathrm{m}]$

$b$ " dynamic properties of O-rings $[1 / \mathrm{kHz}]$

$C_{r}$ radial clearance at the ridge parts [m]

$d_{1} \quad$ inner diameter of the housing [m]

$d_{2} \quad$ outer diameter of the bearing sleeve [m]

$f_{p} \quad$ excitation frequency $[\mathrm{kHz}]$

$H \quad$ groove depth ratio $=\left(\delta+C_{r}\right) / C_{r}$

$k_{b} \quad$ stiffness coefficient of O-rings [MN/m]

$k_{i} \quad$ stiffness coefficients of air film $(i=1,2,3,4)$ $[\mathrm{MN} / \mathrm{m}]$

$k$ dynamic properties of O-rings $[\mathrm{MN} / \mathrm{m}]$

$k$ " dynamic properties of O-rings $[1 / \mathrm{kHz}]$

$m_{b}$ bearing mass $[\mathrm{kg}]$

$p_{a} \quad$ atmospheric pressure $[\mathrm{Pa}]$

$R \quad$ radius of the shaft $[\mathrm{m}]$

$s$ thickness of O-rings [m]

$t$ time [s]

$\alpha \quad$ groove width ratio $=\alpha_{g} /\left(\alpha_{g}+\alpha_{r}\right)$

$\alpha_{r} \quad$ groove width in the ridge parts [m]

$\alpha_{g}$ groove width in the groove parts [m]

$\beta \quad$ groove angle [rad]

$\gamma \quad$ deformation ratio $=\left(2 s-d_{1}+d_{2}\right) / 2 s$ $\theta \quad$ circumferential coordinate

$\Lambda \quad$ bearing number $=6 \mu \omega R^{2} / p_{a} C_{r}^{2}$

$\mu \quad$ viscosity $[\mathrm{Pa} \cdot \mathrm{s}]$

$v \quad$ whirl frequency ratio $=\omega_{p} / \omega$

$\varphi$ phase difference

$\omega$ angular velocity of the shaft $[\mathrm{rad} / \mathrm{s}]$

$\omega_{p}$ angular velocity of the whirl $[\mathrm{rad} / \mathrm{s}]$

\section{References}

[1] Khonsari, M. M., “Applied Tribology,” John Wiley \& Sons, Ltd, 2008, 321.

[2] Lund, J. W., "The Stability of an Elastic Rotor in Journal Bearings with Flexible, Damping Support," ASME Journal of Applied Mechanics, 32, 4, 1965 , 911-920.

[3] Powell, J. W. and Tempest, M. C., "A Study of High Speed Machines with Rubber Stabilized Air Bearings," ASME Journal of Lubrication Technology, 90, 4, 1968, 701-707.

[4] Kazimierski, Z. and Jarzecki, K., "Stability Threshold of Flexibly Supported Hybrid Gas Journal Bearings," ASME Journal of Lubrication Technology, 101, 4, 1979, 451-457.

[5] Belforte, G., Colombo, F., Raparelli, T. and Viktorov, V., "High-Speed Rotor with Air Bearings Mounted on Flexible Supports: Test Bench and Experimental Results," ASME Journal of Tribology, 130, 2, 2008, 021103.

[6] Waumans, T., Peirs, J., Al-Bender, F. and Reynaerts, D., "Aerodynamic Journal Bearing with a Flexible, Damped Support Operating at 7.2 Million DN," Journal of Micromechanics and Microengineering, 21, 2011, 104014.

[7] Ertas, B. H., "Compliant Hybrid Journal Bearings Using Integral Wire Mesh Dampers," ASME Journal of Engineering for Gas Turbines and Power, 131, 2, 2009, 022503.

[8] Ono, K., Iwama, A., Suzuki, M., Iwamura, T., Itami, Y. and Hwang, T., "Analysis and Design of Radial and Thrust Bearing for Polygonal Scanner Rotor-Bearing System," Transactions of the JSME, Series C, 60, 576, 1994, 2670-2678 (in Japanese).

[9] Yoshimoto, S. and Takahashi, A., "A Method of Reducing Windage Power Loss in a Laser Scanner Mirror by Using the Pumping Effect of Herringbone-Grooved Gas Journal Bearings," ASME Journal of Tribology, 121, 3, 1999, 506-509.

[10] Ikeda, S., Arakawa, Y., Hishida, N., Hiyarama, T., Matsuoka, T. and Yabe, H., "HerringboneGrooved Bearing with Non-Uniform Grooves for High-Speed Spindle," Lubrication Science, 22, 9, 2010, 377-392.

[11] Gad, A. M., Nemat-Alla, M. M., Khalil, A. A. and Nasr, A. M., "On the Optimum Groove Geometry for Herringbone Grooved Journal Bearings," 
ASME Journal of Tribology, 128, 3, 2006, 585-593.

[12] Ibrahim, M. D., Namba, T., Ochiai, M. and Hashimoto, H., "Optimum Design of Thrust Air Bearing for Hard Disk Drive Spindle Motor," Journal of Advanced Mechanical Design, Systems, and Manufacturing, 4, 1, 2010, 70-81.

[13] Fesanghary, M. and Khonsari, M. M., "On the Optimum Groove Shapes for Load-Carrying Capacity Enhancement in Parallel Flat Surface Bearings: Theory and Experiment," Tribology International, 67, 2013, 254-262.

[14] Hirasaka, S., Yoshimoto, S. and Yagi, K., "Development of Aerodynamic Bearings for an Ultra-Micro Gas Turbine," Proceedings of JSME Annual Meeting (V), 2003, 281-282 (in Japanese).

[15] Yoshimoto, S., Miyatake, M. and Nagata, K., "Instability of Herringbone Grooved Aerodynamic Floating Bush Bearings Flexibly Supported by Foils with Hemispherical Bumps," Proceedings of ASME/STLE 2007 International Joint Tribology Conference, 2007, 261-263.

[16] Tomioka, J., Miyanaga, N., Outa, E., Takahashi, T., Ogimoto, T., Mori, T. and Kagami, F., "Development of Herringbone Grooved Aerodynamic Journal Bearings for the Support of Ultra-High-Speed Rotors," Transactions of the JSME, Series C, 73, 730, 2007, 1840-1846 (in Japanese).

[17] Tomioka, J. and Miyanaga, N., "Stability
Threshold of Herringbone Grooved Aerodynamic Journal Bearings with External Stiffness and Damping Elements," Transactions of the JSME, Series C, 76, 767, 2010, 1812-1818 (in Japanese).

[18] Tomioka, J. and Miyanaga, N., "Measurement of Dynamic Properties of O-rings and Stability Threshold of Flexibly Supported Herringbone Grooved Aerodynamic Journal Bearings," Tribology Online, 3, 7, 2008, 366-369.

[19] Miyanaga, N. and Tomioka, J., "Stability Threshold of Herringbone-Grooved Aerodynamic Journal Bearings with Considering Frequency Dependence of External Stiffness and Damping Elements," Design Engineering, 46, 4, 2011, 231-238 (in Japanese).

[20] Miyanaga, N. and Tomioka, J., "Stability Threshold of Herringbone-Grooved Aerodynamic Journal Bearings with Considering Temperature Characteristics of Support O-rings," Design Engineering, 46, 9, 2011, 530-535 (in Japanese).

[21] Somaya, K., Okubo, K., Miyatake, M. and Yoshimoto, S., "Threshold Speed of Instability of a Herringbone-Grooved Rigid Rotor with a Bearing Bush Flexibly Supported by Straight Spring Wires," Proceedings of ASME Turbo Expo 2015: Turbine Technical Conference and Exposition, 2015, GT2015-43161.

[22] Nippon Valqua, "Valqua O-rings," Catalogue No.LC01, 2010, 4 (in Japanese). 